

\title{
Designing at the Intersection of Gamification and Persuasive Technology to Incentivize Energy-Saving
}

Böckle Martin, Yeboah-Antwi Kwaku

\section{To cite this version:}

Böckle Martin, Yeboah-Antwi Kwaku. Designing at the Intersection of Gamification and Persuasive Technology to Incentivize Energy-Saving. 18th Conference on e-Business, e-Services and e-Society (I3E), Sep 2019, Trondheim, Norway. pp.316-328, 10.1007/978-3-030-29374-1_26 . hal-02510109

\section{HAL Id: hal-02510109 \\ https://hal.inria.fr/hal-02510109}

Submitted on 17 Mar 2020

HAL is a multi-disciplinary open access archive for the deposit and dissemination of scientific research documents, whether they are published or not. The documents may come from teaching and research institutions in France or abroad, or from public or private research centers.
L'archive ouverte pluridisciplinaire HAL, est destinée au dépôt et à la diffusion de documents scientifiques de niveau recherche, publiés ou non, émanant des établissements d'enseignement et de recherche français ou étrangers, des laboratoires publics ou privés. 


\title{
Designing at the Intersection of Gamification and Persuasive Technology to Incentivize Energy-Saving
}

\author{
Böckle Martin ${ }^{1}$ and Yeboah-Antwi Kwaku ${ }^{1}$ \\ ${ }^{1}$ BCG Platinion, Design and Engineering, Berlin, Germany \\ \{boeckle.martin, yeboah-antwi.kwaku\}@bcgplatinion.com
}

\begin{abstract}
Gamified persuasive system design refers to design solutions at the intersection of gamification and persuasive technology aiming at influencing attitude and behavior change. Although both concepts have been successfully applied in many domains to increase end-user engagement and satisfaction, results are often mixed and highly context specific. Consequently, there is a dearth of knowledge on how to design those solutions and how they are perceived by different types of users within certain application contexts. Thus, this paper investigates the relationship between the HEXAD gamification user types and persuasive principles within the context of energy saving. First results reveal $(\mathrm{n}=206)$ that, three out of six persuasive principles (Reciprocity, Consistency \& Commitment, Liking) have been perceived as persuasive by identified HEXAD user types, which highlights the importance of such user types models. Finally, this paper contributes to the present body of gamification literature by providing a human computer interaction (HCI) perspective which highlights guidelines for designing gamified persuasive systems to incentivize energy-saving.
\end{abstract}

Keywords: Gamification; Persuasive Technology; User-Types; Persuasive Principles; User-Centered Design

\section{Introduction}

In recent years, the use of information technology to foster the end-user engagement to enhance the individual level of energy conservation is becoming increasingly important $[32,33,18]$. Best practices for designing such solutions are being discussed within two research streams in the current body of persuasive literature:

Firstly, persuasive technology (PT), which aims to change human attitudes and behavior [16] where "computers function as persuasive tools (e.g., leading people through a process), social actors (e.g., rewarding people with positive feedback) and as a medium (e.g., providing people with experiences that motivate)" [10, p. 25]. Secondly, the research stream of gamification is focusing on the creation of playful experiences in order to increase overall engagement through the use of game design elements in nongame contexts [6]. This track has received great attention from researchers and practitioners and is being applied in many domains such as education [11], health [29], and 
crowdsourcing [24]. Gamification is still in its infancy, compared to the more established research stream of persuasive technology (PT), although both concepts share common aspects of aiming at influencing attitude and behavior through technology, as discussed in [14].

We believe that design solutions at the intersection of gamification and persuasive technology reveal promising potential. Solutions such as the consideration of different types of persuasive messages within gamified environments, particularly in combination with the gamification feedback mechanic, have often been neglected. Although, several game-design elements have been successfully applied to improve the overall end-user engagement, their effectiveness is often mixed, highly context specific and varies among different types of users [2]. This highlights the pitfalls of a "one size fits all" approach and the need for much more personalization in order to increase the enduser engagement of a broad range of individuals [3].

Though existing research refers to promising concepts of using personality traits for persuasive system design, there is a dearth of design knowledge which highlights best practices for the application of gamification user-types in specific application context, which also includes energy saving. Therefore, this paper aims to investigate the relationship between the HEXAD gamification user types [21] (Philanthropist, Disruptor, Socializer, Free Spirit, Achiever and Player) and the six persuasive principles of Cialdini [5] in order to highlight solutions, which aim to incentivize energy saving. This paper contributes to the present knowledge of human-computer interaction by answering the following research question:

RQ: To which extent do the different HEXAD user-types respond to different persuasive principles when these are applied to the design of a persuasive system for energy saving?

Our results cover design solutions and supports researchers and practitioners in the creation of gamified persuasive system design in order to incentivize energy-saving. To the best of our knowledge, this is the first study which investigates the intersection and relationship between the HEXAD gamification user types and the six persuasive principles of Cialdini [5].

\section{Research Background}

\subsection{Persuasive Technology and Principles}

The research stream of persuasive technology was primarily introduced by the work of $[10,9]$ who proposed the term persuasive system design (PSD) and presented twentyeight persuasive strategies, which have gained widespread acceptance and are based on the principles of Fogg [10]. Within this paper we focus on the six persuasive principles proposed by [5], which have gained considerable attention but have not been tested within the energy domain so far. Existing research has already paid attention to the relationship of game design elements and user types $[11,8]$. This also includes articles on persuasive strategies and user type models [27], however the investigation of the relationship between the HEXAD gamification user types and the persuasive principles by Cialdini (2001) is currently missing and reveals promising potential for persuasive 
system design of energy-saving applications. The six persuasive principles will be explained in more detail:

- Liking refers to the phenomenon of "we say yes to people we generally like" [5]. According to [4], research has shown that people are more willing to purchase insurance policies from a salesperson with similarities in age, religion, politics or smoking habits.

- Reciprocity describes the norm that obligates people to repay in kind, a favor which they have received [5]. This principle is specifically strong and is also described as "give what you want to receive" [4, p. 75].

- Scarcity refers to the fact that "items and opportunities become more desirable to us if they become less available" [5, p. 80] and is described as people want more of what is less available [4].

- Authority highlights that axiom that "people defer to experts" [4, p. 77] meaning that if a request or statement is made by a legitimate authority, there is a propensity for people to accept the request or definitions of action "irrespective of the content of the act and without limitations of conscience" [23, p. 24].

- Consistency and Commitment reveals, that "people do as they said they would" [19, p. 1174]. This principle shows that the likelihood of people actively making choices is higher when the choices are "spoken out loud or written down actively" [4, p. 76] the choices become more powerful when they are made public.

- Consensus describes the principle of "people do as other people do" [19, p. 1174] and highlights that people "follow the lead of similar others" [4, p. 75]. The principle is also termed social validation [5] or social proof [4], meaning that if a group of individuals decide to go in a specific direction, others are more likely to follow because they perceive this direction to be more correct and valid [5].

\subsection{Player Typologies}

Generally, player types represent a useful concept for the definition of boundaries [22] in order to ensure the efficiency and effectiveness of the overall game design. Research shows that personality types play an important role and have an effect on player typologies, (e.g., BrainHex archetypes by [25]; or the HEXAD user types by [21]) as well as preferences and game design elements. The most frequently used player types, are the ones by Bartle [1], namely "Killer, Achiever, Socializer and Explorer", however these should not be generalized to gameful design as mentioned in [30], because their relation towards actual video games. Therefore, within this paper, we selected the HEXAD gamification user types framework, which has been developed to ensure gameful design with a high degree of personalization for mapping user types and game design elements. Within this paper we applied the HEXAD gamification user types framework consisting of the following six user types, described in Table 1:

Table 1. Gamification User Types HEXAD [30, p. 231]

Philanthropists are motivated by purpose and meaning. This type of user is willing to give without expecting a reward. 




Existing research presents the validation of player types (achievers, explorers, philanthropists, socializers) and their relationship to gamification mechanics inside an elearning environment [11] with mixed results. Similarly, the work of [26] shows the connections between the big-five factor model ([12] FFM - openness, conscientiousness, extraversion, agreeableness, neuroticism) and the perceived persuasiveness towards selected persuasive principles to provoke behavior change of unhealthy drinking.

The study of [27] emphasizes the persuasiveness between the BrainHex typologies and persuasive strategies and includes the novel development of persuasive profiles. The authors suggest the following steps to the personalization of persuasive games towards their gamer types: "(1) Determine the gamer groups; (2) Decide on the design approach; (3) Map strategies to game mechanics" [27, p. 458]. The last step of "Map strategies to game mechanics" is actually covered by this paper and we highlight the importance of this mapping process.

\section{$3 \quad$ Research Design}

For the investigation of the relationship between the HEXAD gamification user types and the persuasive principles for energy saving, a survey with storyboards, which covers each of the persuasive principles within a predefined energy saving context, was designed. We came up with persuasive messages, which were then defined and integrated in the feedback mechanic of a mobile energy-saving application.

Two example storyboards are described in Figure (1): On the left-hand side, the persuasive message for Reciprocity $(S 1)$ is designed as a reminder to invite more people to the energy-saving application after receiving a badge for the overall positive energy consumption. The user's willingness to act is expected to be higher after receiving an award from the system, which covers the principle of Reciprocity. The second example represents Liking (S6) where geographically close friends reduced their consumption by $30 \mathrm{kWh}$. This is expected to persuade the friends to follow them and adopt a similar energy-consumption behavior. The following Table describes the persuasive message within the gamification feedback mechanic:

Table 2. Persuasive messages within the storyboards

Reciprocity (S1): You just received the "Loyal Energy Saver Badge" for being a frequent system user. Please invite more users to the energy application through the e-mail form.

Commitment and Consistency (S2): You defined your personal energy-saving goal up to 
$+20 \%$ this month. You miss $5 \%$ to reach your goal. Try to reduce your energy consumption in the next days.

Scarcity (S3): This is the last chance to receive the "Energy Saving Enthusiast Badge" this month. Score at least 50 points more this week in order to receive it.

Authority (S4): According to the global energy authority, your current consumption is over average and very high. Follow their guidelines and try to reduce your current consumption by $30 \%$.

Consensus (S5): Four energy users from your neighborhood decreased their consumption by $25 \mathrm{kWh}$ this month. Follow their profiles and consumption patterns in order to reduce your current consumption.

Liking (S6): Four of your friends decreased their consumption by $30 \mathrm{kWh}$ this month. Follow their profiles and consumption patterns in order to reduce your current consumption.


Fig. 1. Sample Story-Board (Reciprocity - left; Liking - right)

In order to obtain feedback for each storyboard, the scale [7] for measuring the perceived persuasiveness has been added to the survey questions. The perceived persuasiveness is assessed on a seven-point Likert scale: (1 - strongly disagree; 7 - strongly agree) through the following questions: (1) This system would influence me; (2) This system would be convincing; (3) This system would be personally relevant for me; (4) This system would make me reconsider my energy consumption habits. The HEXAD gamification user types provide a questionnaire for the identification of those types, described in [30].

To answer our research question, we applied partial least square structural equation modeling (PLS-SEM), which provides approaches and techniques to investigate the relationship between the HEXAD gamification user types and the persuasive principles of [4], visualized in Figure (2). Furthermore, to perform structural equation modeling (SEM), we used SmartPLS, which provides solutions for path modeling [31]. The PLSSEM model has been defined as following: As visualized in Figure (2), each HEXAD user type on the left-hand side and persuasive principle on the right represents a latent variable. The values for the user types were collected through the HEXAD survey. On the right-hand side, the perceived persuasiveness for each principle has been listed. In order to investigate the relationship between user types and principles, each player type has been connected with each persuasive principle. 


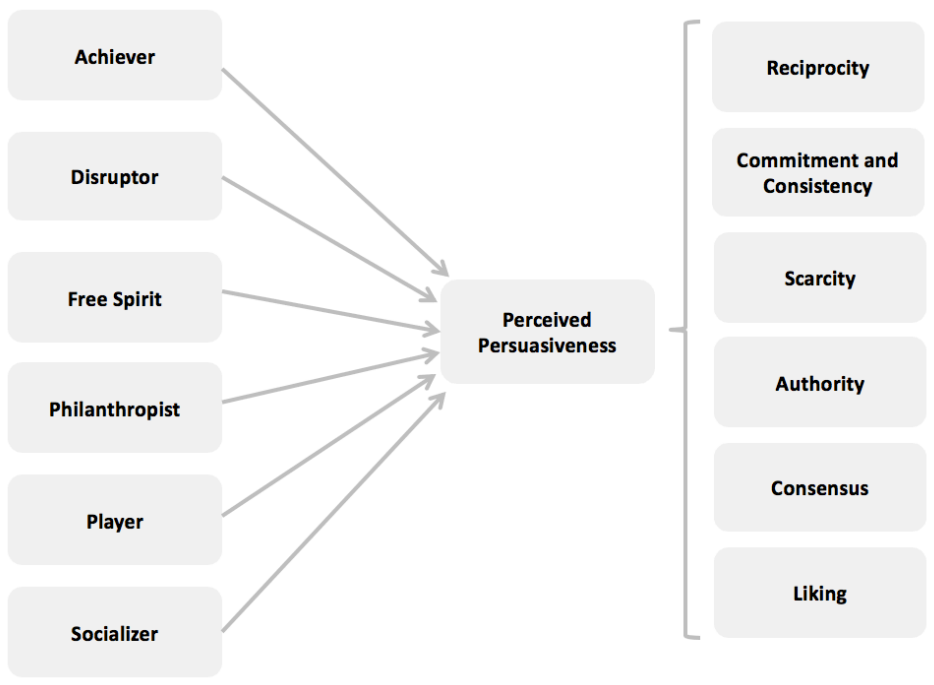

Fig. 2. PLS-SEM Model

\section{$4 \quad$ Results}

Generally, to ensure model reliability in PLS-SEM we considered the following criteria for our collected data: Firstly, the Cronbach's $\alpha$ represents a standard indicator for reliability within PLS-SEM and revealed a value above 0.8 and therefore passes the threshold of 0.7. Secondly, the heterotrait-monotrait ratio (HTMT) represents an index for discriminant validity [15], which was below the threshold value of 0.85 for all the relationships. Thirdly, the average variance extracted (AVE) was above the recommended threshold of 0.5 for all the items we used. Results have been acquired through the micro-task platform Mechanical Turk (MTurk). Using this platform as a method for obtaining reliable results of end-user's responses is widely accepted [28] and has been used within a variety of studies with a human-computer-interaction (HCI) focus [27] as well as gamification research [17]. In order to provide high quality results, we followed best practices recommended by $[20,13]$ by setting a high approval rate $(97 \%$ and above), combined with an approved number of HITs (5000 and above).

\subsection{Demographic Information}

We received 205 valid responses through Mechanical Turk from a diverse group of end-users. Results on demography highlight that $56 \%$ of end-users were male. The majority ( $53 \%$ ) has an age between 26 and 35, whereas 52\% had obtained a bachelor's degree. Furthermore, most of the end-users were from the USA (60\%) and India (37\%).

Table 3. Demographic information

\begin{tabular}{l|l}
\hline Total responses $(\mathbf{n}=\mathbf{2 0 5})$ \\
\hline Gender & Female $(44 \%)$, Male $(56 \%)$, Trans $(0)$, Others $(0)$ \\
\hline
\end{tabular}




\begin{tabular}{l|l}
\hline Age & $15-25(18 \%), 26-35(53 \%), 36-45(11 \%)$, Over 45 (18\%) \\
\hline Education & $\begin{array}{l}\text { Less than high school (2\%), High school (14\%), Graduate (11\%), College di- } \\
\text { ploma (8\%), Bachelor's degree (52\%), Master's degree (10\%), Doctoral de- } \\
\text { gree (1\%), Other }(2 \%)\end{array}$ \\
\hline Country & USA $(60 \%)$, India $(37 \%)$, Netherlands $(0.5 \%)$, Germany $(2 \%)$, Canada $(0.5 \%)$ \\
\hline
\end{tabular}

\subsection{Persuasive Principles}

After defining the model, we applied the PLS algorithm, in order to reveal the path coefficient $\beta$, which explains the effect of one variable on another [31]. Furthermore, we bootstrapped the results and derived t-statistics, which provide the p-value for each of the calculated paths in order to understand the significance of this relationship, highlighted in Table (4):

Table 4. Path coefficients $\beta$ (significant relationships - bold)

\begin{tabular}{l|l|l|l|l|l|l}
\hline Persuasive Principle & PHI & SOC & FRE & ACH & PLA & DIS \\
\hline Reciprocity & -0.04 & 0.07 & -0.09 & -0.06 & $\mathbf{0 . 1 7 *}$ & $\mathbf{0 . 1 5 *}$ \\
\hline Commitment and Consistency & 0.12 & 0.09 & $\mathbf{- 0 . 2 4 *}$ & $\mathbf{0 . 1 7 *}$ & -0.00 & $\mathbf{0 . 1 3 *}$ \\
\hline Scarcity & -0.04 & 0.06 & -0.00 & 0.106 & 0.01 & 0.08 \\
\hline Authority & 0.01 & 0.12 & 0.08 & 0.04 & -0.03 & 0.04 \\
\hline Consensus & -0.00 & 0.10 & -0.01 & 0.02 & -0.05 & 0.16 \\
\hline Liking & -0.12 & 0.07 & -0.13 & -0.07 & 0.12 & $\mathbf{0 . 2 0 *}$ \\
\hline
\end{tabular}

Path coefficient beta $(\beta)$ and the level of significance $(p)$ between player types and persuasive strategies (*coefficient $\mathrm{p}<.05$ ), PHI - Philanthropist, SOC - Socializer, FRE - Free Spirit, $\mathrm{ACH}-$ Achiever, PLA - Player, DIS - Disruptor

Reciprocity: Results show that the gamified persuasive principle Reciprocity only motivates end-users with a high tendency towards the Player $(\beta=0.17, \mathrm{p}<0.05)$ and Disruptor $(\beta=0.15, \mathrm{p}<0.05)$ user type. These results confirm that the Player type is motivated by extrinsic rewards like rewards, suggested and supported in [30], since S1 (storyboard) includes a badge within the gameful design. While the Player user type has a strong relationship towards rewards, Disruptors are motivated by change [30] and disrupt the system in a positive or negative way and try to push further [30]. Finally, end-users with a high tendency towards Disruptors $(\beta=0.15, \mathrm{p}<0.05)$ are motivated by the Reciprocity principle, which shows that the Disruptor user type is motivated by gamified reciprocity approaches and pushes towards change. The small preference by the user-type Philanthropist, Socializer and Free Spirit could have several reasons. Socializers tend to prefer social interactions and are motivated by relatedness, which has been less covered by the first storyboard (S1), representing Reciprocity. Furthermore, Free Spirits like to act by themselves [30], without external control, meaning that a 
feedback mechanic suggesting a call to action may not persuade this type of users, who are motivated by autonomy. Similarly, the Philanthropist user type is willing to give without expecting a reward, with a focus on purpose, and this is not addressed by the first storyboard.

Commitment and Consistency: Results of the Commitment and Consistency reveal that people with a high tendency towards the Achiever $(\beta=0.17, \mathrm{p}<0.05)$ and Disruptor $(\beta=0.13, \mathrm{p}<0.05)$ user type are motivated by this principle. According to [30], Achievers seek to progress within a system. This supports our results by referring to the goal-setting functionality within the defined gamification approach of S2. In addition, the Disruptor user type is motivated by this principle, which shows that goal-setting functionalities could enable end-users towards change. Finally, people with a high tendency towards Free Spirit are demotivated by this principle as the user-type is motivated by autonomy. Generally, this user-type prefers creativity tools, unlockable content or non-linear gameplay, which shows that persuasive principles could also have negative effects for a certain group of end-users. The principle has not been considered as motivating by the user-type Philanthropist, Socializer and Player. As the second storyboard (S2) does not include any social components, nor badges or scores, the results reflect the aim and design of the player types.

Scarcity, Authority \& Consensus: Unfortunately, we could not identify any significant motivator between the persuasive principle Scarcity and the HEXAD user types. The Scarcity principle is based on the weakness for shortcuts of people. In the case of S3 the availability of certain badges should be equal to the quality and from a psychological perspective, the limited choice should increase the feeling to own the "Energy Saving Enthusiast". The reason for the low motivational effects by any of the HEXAD user types could be related to the setting of the storyboard, as the Scarcity effect may work better when end-users already own certain badges and scores and are aware of the value and impact of these game design elements, especially for the Player user type, who is motivated by extrinsic rewards. For the Authority principle, the user-type Disruptor, who is triggered by change could have shown a higher tendency towards this principle. Generally, the overall design of the Authority does not completely fit in with the rest of the user types and may only work in specific use cases (e.g., education), where people might listen to reminders from a higher instance (e.g., teacher). The Consensus principle is showing similar results, presented as a leaderboard with a list of geographically close neighbors and their improved energy-conservation profile. The system provided a feedback message that neighbors decreased their consumption by $30 \mathrm{kWh}$ and included a call to action titled "Start Following". Although, there were no tendencies from any of the HEXAD user types towards the Consensus principle, Liking follows a similar design, but uses friends instead of neighbors within the defined storyboard (S6) and reveals a significant relationship with the Disruptor user-type. This supports our assumption that motivational effects are higher when they are used within an environment where the end-users know each other, as demonstrated by the result of the Liking principle. This also includes the awareness of already collected rewards, scores including their impact and value after an intense usage of the application.

Liking: Results show that the Liking principle motivates people with a high tendency towards the Disruptor user type $(\beta=0.2, \mathrm{p}<0.05)$, which confirms that end-users prefer environments with people they know compared to the Consensus principle where we 
did not identify any significant results. Although, Liking has been preferred by people with a high tendency towards the Disruptor user type which shows that people with those characteristics prefer positive change and to push further, the Socializer user type did not show any preferences for S6. This could be due to several reasons: Firstly, the usage of the design element Leaderboard is more preferred by the Player user type, described in [30] and people with a high tendency towards Socializers prefer the interaction itself [30].

\section{Discussion and Limitations}

For the identified persuasive principles (Reciprocity, Commitment \& Consistency, Liking), which reveal a significant relationship with the HEXAD user types, we came up with the following design guidelines (Table 5) to offer the opportunity to personalize and design for certain groups of users. The design guidelines consist of well-known game design elements and text messages, provided by the system within the feedback mechanic, which are used in combination with a call to action button:

Table 5. Design guidelines

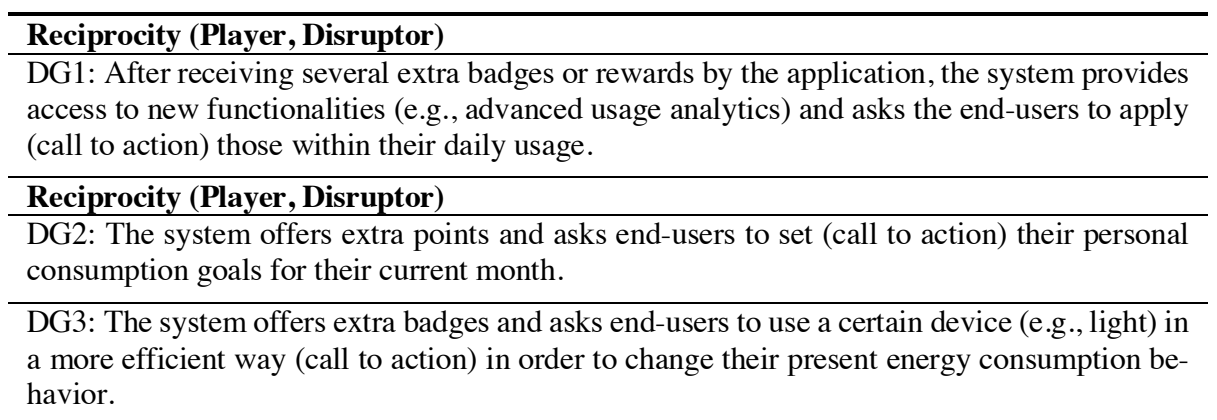

Commitment and Consistency (Achiever, Disruptor)

DG4: The application offers goal-setting functionalities in combination with levels and status ("e.g., energy-saving starter - energy-saving enthusiast etc.) and reminds end-users about their consumption goals, status, progression and suggest incentives in order to reach the next level (call to action - e.g., apply this well-known energy-saving tip and receive additional 50 points).

DG5: The system reminds end-users about their past energy-saving behavior and comes up with new challenges in order to tackle them and improve their current consumption.

DG6: The system provides several options for end-users to set their level of importance for reaching defined consumption goals and sends reminders and incentives in case of any negative deviations (e.g., reducing power for the fridge has been set as very important by you; reduce it now). Energy-saving goals are connected to certificates and status within the application.

\begin{tabular}{l}
\hline Liking (Disruptor) \\
\hline DG7: The system reminds end-users that friends also apply the following best practice energy \\
saving tip (e.g., use different light bulbs - update them now and receive extra points). \\
\hline DG8: The application lists energy-saving profiles based on consumption metrics of friends \\
and asks the user to adapt to similar behavior patterns and recommends actions and incentives
\end{tabular}


("e.g., follow your friends and reduce consumption by installing a smart thermostat). This functionality also includes a voting system for nominating friends who perform best.

DG9: The system offers group functionalities like closed groups, chats and visualizations where consumption behaviors and tips can be shared with other friends. Energy-saving tips include voting functionalities.

Generally, we identified four HEXAD user types (Disruptor, Player, Achiever, Free Spirit), which reveal a high tendency of perceived persuasiveness towards three principles (Reciprocity, Commitment \& Consistency, Liking) and came up with design guidelines for gamified energy saving applications.

In addition, we confirm and highlight the importance of user-type models within the design of gamified persuasive system for energy-saving. Although our approach reveals promising results, there are few limitations to consider. First, we used static storyboards which represent the six persuasive principles by [4] and asked end-users about the perceived persuasiveness. Although, storyboards represent a valid method to investigate preferences for certain types of users, persuasive principles may be more effective if they are used in a real-world application, especially when gamification elements are used. Especially, the everyday usage would probably reveal the strength and weaknesses of each strategy in a more meaningful way. For instance, the Achiever user type prefers levels or progression. Persuasive principles may show it's potential to the full extent if the end-users find themselves in a certain context, which can't be represented by storyboards in general (e.g., already collected certain amount of score, badges or situations where end-users find themselves in situations like crossing the next level or stage within the application). Certain contexts and the efficiency of persuasive principles within these contexts are not only difficult to measure, but also the collection of results through MTurk may reveal cultural aspects, which cannot be considered, for example energy-saving behaviors may differ remarkable between different countries or cultures. Finally, future research should pay attention to existing energy-consumption behaviors and how these can be incorporated into the design to provide more contextual guidelines by considering different cultures, gender and age groups.

\section{Conclusion}

This paper explores design possibilities at the intersection of gamification and persuasive technology (PT) within the energy-saving domain by investigating the relationship between the HEXAD gamification user types and the six persuasive principles, proposed by Cialdini [4]. The main contribution is therefore twofold: Firstly, we identified which user types show a high tendency towards the designed storyboard of the six persuasive principles in order to inform researchers and practitioners for designing more personalized gamified applications with persuasive elements in text format. Furthermore, we derived design guidelines which reveal best practices for designing consumption-focused environments in order to provide a more general perspective. Secondly, we validated the usage of persuasive principles of Cialdini [4] within gamified environments, which has not been investigated so far and thus contribute towards the present body of human-computer interaction (HCI) knowledge. Furthermore, we identified 
several design solutions where HEXAD user-types show significant values for the perceived persuasiveness of the gamified persuasive system designs. Although only three out of six persuasive principles show significant results towards certain HEXAD gamification user types, we think that designing at the intersection of gamification and persuasive technology offers manifold opportunities, which has been researched very little. Consequently, this paper has a high explorative character and represents a showcase that demonstrates how to combine persuasive text messages within game design elements to incentivize energy-saving.

\section{References}

1. Bartle, R.: Hearts, Clubs, Diamonds, Spades: Players who suit MUDs. Journal of MUD Research, Volume 1 (1996)

2. Böckle, M., Micheel, I., Bick, M., and Novak, J.: A Design Framework for Adaptive Gamification Applications. In: Proceedings of the HICSS-51, Waikoloa, Hawaii, USA (2018)

3. Böckle, M., Novak, J., and Bick, M.: Towards Adaptive Gamification: A Synthesis of Current Developments. In: Proceedings of the Twenty-Fifth European Conference on Information Systems (ECIS), Portugal (2017)

4. Cialdini, R. B.: Harnessing the Science of Persuasion. Harvard Business Review (2001)

5. Cialdini, R. B.: The science of persuasion. Scientific American Mind, 284, pp. 76-84 (2004)

6. Deterding, S., Dixon, D., Kahled, R., and Nacke, L.: From game design elements to gamefulness: defining gamification. In: Proceedings of the 15th International Academic MindTrek Conference: Envisioning Future Media Environments. pp. 9-15, Tampere, Finland (2011)

7. Drozd, F., Lehto, T., and Oinas-Kukkonen, H.: Exploring perceived persuasiveness of a behavior change support system: A structural model. In: Proceedings of Persuasive 2012, LNCS, pp. 157-168 (2012)

8. Ferro, S.L., Walz, P.S., and Greuter, S.: Towards personalised, gamified systems: an investigation into game design, personality and player typologies. In: Proceedings of the 9th Australasian Conference on Interactive Entertainment, 1-6, Melbourne, Australia (2013)

9. Fogg, B. J.: Persuasive computers: Perspectives and research directions. In: Proceedings of CHI 98, pp. 225-231, Los Angeles, USA (1998)

10. Fogg, B. J.: Persuasive Technology: Using Computers to Change What We Think and Do. Morgan Kaufmann Publishers, Burlington, MA, USA (2002)

11. Gil, B., Cantandor, I., and Marczewski, A.: Validating Gamification Mechanics and Player Types in an E-Learning Environment. In: Proceedings of EC-TEL 2015, pp. 568-572, Toledo Spain (2015)

12. Goldberg, L. R.: An alternative description of personality: The Big-Five factor structure. Journal of Personality and Social Psychology, 59, pp. 1216-1229 (1990)

13. Goodman, K. J, Cryder, E.C., and Cheema, A.: Data collection in a flat world: The strengths and weaknesses of Mechanical Turk samples. Journal of Behavioral Decision Making, 26, 213-224 (2012)

14. Hamari, J., Koivisto, J., and Pakkanen.: Do persuasive technologies persuade? - A review of empirical studies. In Proceedings of the International Conference on Persuasive Technology 2014, pp. 118-136, Padua, Italy (2014)

15. Henseler, J., Ringle, M. C., and Sarstedt, M.: A new criterion for assessing discriminant validity in variance-based structural equation modeling. Journal of the Academy of Marketing Science, 43(1), pp. 115-135 (2015) 
16. Ijsselsteijn, W., De Kort, Y., Midden, C., Eggen, B., and Van Den Hoven, E.: Persuasive technology for human well-being: Setting the scene. Lecture Notes in Computer Science, LNCS, 3962 (2006)

17. Jia, Y., Xu, B., Karanam, Y., and Voida S.: Personality-targeted gamification: A survey study on personality traits and motivational affordances. In Proceedings of CHI 2016, pp. 20012013, San Jose (2016)

18. Johnson, D., Horton, E., Mulcahy, R., and Foth, M.: Gamification and serious games within the domain of domestic energy consumption: A systematic review. Renewable and Sustainable Energy Reviews, 73, pp. 249-264 (2017)

19. Kaptein, M., and Van Halteren, A.: Adaptive persuasive messaging to increase service retention: using persuasion profiles to increase the effectiveness of email reminders. Personal Ubiquitous Computing, 17, pp. 1173-1185 (2013)

20. Kittur, A., Chi, E. H., and Suh, B.: Crowdsourcing user studies with Mechanical Turk. In Proceedings of CHI 2008, Florence, Italy (2008)

21. Marczewski, A.: User types. In: Even Ninja Monkeys Like to Play: Gamification, Game Thinking \& Motivational Design. CreateSpace Publishing Platform, pp. 69-84, (2015)

22. Meder, M., Plumbaum, T., and Albayrak, S.: Learning Gamification Design - An Usability First Approach for the Enterprise Infoboard Experiment. In: Proceedings of the GamifIR Workshop, Pisa, Italy (2016)

23. Milgram, S.: Obedience to authority. London: Travistock (1974)

24. Morschheuser, B., Hamari, J., and Koivisto, J.: Gamification in Crowdsourcing. In: Proceedings of HICSS 49, USA (2106)

25. Nacke, L.E., Bateman, C., Mandryk, R. L: BrainHex: Preliminary Results from a Neurobiological Gamer Typology Survey. Entertainment Computing, Volume 5, Issue 1 (2014)

26. Orji, R., Nacke, L. E., and Di Marco, C.: Towards personality-driven persuasive health games and gamified systems. In: Proceedings of CHI 2017, Denver, USA (2017)

27. Orji, R., Vassileva, J., and Mandryk, R. L.: Modeling the efficacy of persuasive strategies for different gamer types in serious games for health. User Modeling and User-Adapted Interaction, 24(5), pp. 453-498 (2014)

28. Paolacci, G., \& Chandler, J.: Inside the Turk: Understanding Mechanical Turk as a participant pool. Current Directions in Psychological Science, 23(3), pp. 184-188 (2014)

29. Pereira, P., Duarte, E., Rebelo, F., and Noriega, P.: A Review of Gamifcation for HealthRelated Contexts. In: Proceedings of DUXU 2014, LNCS, pp. $742-753$ (2014)

30. Tondello, F. G., Wehbe, R. R., Diamond, L., Busch, M., Marczewski A., and Nacke, L.: The gamification user types Hexad Scale. In: Proceedings of CHI Play 2016, pp. 229-243 (2016)

31. Wong, K. K.: Partial least squares structural equation modeling (PLS-SEM) techniques using SmartPLS. Marketing Bulletin, 24(1), pp. 1-32

32. Lounis, S., Neratzouli, X. and Pramatari. K.: Can gamification increase consumer engagement? A qualitative approach on a green case. In: Proceedings of I3E - Conference on eBusiness, e-Services and e-Society, pp. 200-212, Athens (2013)

33. Peham, M., Breitfuss, G. and Michalczuk, R.: The ecogator app: gamification for enhanced energy efficiency in Europe. In: Proceedings of the Second International Conference on Technological Ecosystems for Enhancing Multiculturality, pp. 179-183, Salamanca, Spain (2014) 